\title{
Fine-Resolution Physical Mapping of Genomic Diversity in Candida albicans
}

\author{
Hiroji Chibana, ${ }^{1}$ Janna L. Beckerman, and P.T. Magee \\ Department of Genetics, Cell Biology, and Development, University of Minnesota, St. Paul, Minnesota 55108, USA
}

\begin{abstract}
It has been suggested that Candida albicans, a diploid asexual fungus, achieves genetic diversity by genomic rearrangement. This important human pathogen may provide a system in which to analyze alternate routes to genomic diversity. C. albicans has a highly variable karyotype; its chromosomes contain a middle repeated DNA sequence called the Major Repeat Sequence (MRS), composed of subrepeats HOK, RPS, and RB2. RPS is tandemly repeated while the other subrepeats occur once in each MRS. Chromosome 7, the smallest of the eight chromosomes, has been previously mapped. The complete physical map of this chromosome was used to analyze chromosome 7 diversity in six strains, including two well-characterized laboratory strains (1006 and WO-1) and four clinical ones. We found four types of events to explain the genomic diversity: 1) Chromosome length polymorphism (CLP) results from expansion and contraction of the RPS; 2) reciprocal translocation occurs at the MRS loci; 3) chromosomal deletion; and (4) trisomy of individual chromosomes. These four phenomena play an important role in generating genomic diversity in C. albicans.
\end{abstract}

Candida albicans is the most common fungus responsible for oral and vaginal infection and causes systemic disease in immunocompromised hosts, such as patients who have undergone organ transplants or those undergoing intensive chemotherapy (Musial et al. 1988). In this diploid organism, for which a sexual cycle has not yet been found, evidence supports clonal propagation, at least primarily (Pujol et al. 1993; Lott et al. 1999). Despite the asexual lifestyle, C. albicans shows frequent karyotypic variation (Iwaguchi et al. 1990; Rustchenko-Bulgac 1991; Magee et al. 1992). This could be problematic in a fungus that regularly undergoes meiosis (Kistler and Miao 1992). However, in a population that undergoes clonal propagation, the diversification of karyotype will be acceptable if the progeny are viable (reviewed in Zolan 1995). Karyotypic variation has been reported in species that undergo clonal propagation (Mills and McCluskey 1990; Zolan 1995; Fierro and Martin 1999). However, the molecular mechanisms for karyotypic variation have not yet been clarified.

There are numerous reports of karyotypic diversity in C. albicans with chromosome size ranging from 4 Mbp to 0.5 Mbp (Snell and Wilkins 1986; Lott et al. 1987; Magee and Magee 1987; Lasker et al. 1989; Iwaguchi et al. 1990; Asakura et al. 1991; RustchenkoBulgac. 1991; Wickes et al. 1991). Suzuki et al. (1989) and Rustchenko-Bulgac et al. (1990) proposed that there was a correlation between the diversity of karyotype and diversity of phenotype. Several reports com-

'Corresponding author.

E-MAIL chibana@biosci.cbs.umn.edu; FAX (612) 625-5754. Article and publication are at www.genome.org/cgi/doi/10.1101/ gr. 148600 . paring karyotypic change and phenotypes-such as the ability to switch (Ramsey et al. 1994), assimilation of carbon source (Rustchenko et al. 1994 ), and resistance to the antifungal drug fluconazole (Mori et al. 1998)have been published. Despite great effort, no correlation between the diversity of karyotype and diversity of phenotype was shown until Rustchenko and coworkers found an association between the loss or partial deletion of one of the homologs of chromosome 5 and assimilation of sorbose (Janbon et al. 1998). Subsequently, a correlation between the loss of one of the homologs of chromosome 4 and resistance to fluconazole was shown (Perepnikhatka et al. 1999).

These findings have led to the notion that gain of a new niche by karyotypic alteration leading to changes in the phenotype is an adaptation strategy of C. albicans, and the nature of the genome of this fungus has thus become an important subject. Many efforts have been made to understand the mechanism by which diversity is generated in the karyotype in C. albicans. Iwaguchi et al. (1990) and Thrash-Bingham and Gorman (1992) suggested that reciprocal chromosome translocation would account for many of the observed changes in the karyotype.

Iwaguchi et al. (1992a) cloned and characterized a repeated sequence, RPS (2 kbp), which is found on all chromosomes except chromosome 3 . The number of RPS units present is dependent on both the strain and the chromosomal location. Chu et al. (1993) completed SfiI macro restriction maps of 1006 and WO-1 and showed that, in the latter strain, three reciprocal chromosomal translocations occurred near the SfiI sites. Later, it was found that the Sfil sites were highly conserved in the RPS sequences of different chromosomes (Chibana et al. 1994) and that the RPS is tan- 
demly repeated between the SfiI fragments of chromosome 5 (Chindamporn et al. 1995) and of chromosome 7 (Chibana et al. 1998). Flanking the RPS sequences are additional repetitive elements RB2 (6 kbp) and HOK (8 kbp) (Chindamporn et al. 1998). The complete repeat unit is referred to as the Major Repeat Sequence (MRS) and is composed of HOK, RPS, and RB2, in that order (Chibana et al. 1998).

In this study, we confirm that the MRS plays a major role in the changes that lead to karyotypic diversity in C. albicans. The variations in karyotype of several clinical isolates are shown to result from translocations and chromosome length polymorphism (CLP), both involving the MRS. Thus, the RPS element serves as both a breakpoint for chromosomal translocations and, through expansion of its number of internal repeats, a major source of size variation between homologs. We have mapped karyotypic rearrangements to high resolution in several clinical isolates of C. albicans and compared them to strain 1006, the source of the mapping part of the C. albicans Genome Project (http://alces.med.umn.edu/candida.html). This study shows that the MRS is involved in CLP and supports the model that it serves as a site of ectopic pairing for recombination leading to translocations be- tween nonhomologous chromosomes. This shows a mechanism of karyotypic rearrangement that may serve as a model for chromosomal rearrangements in a variety of fungi. We show a role of MRS for karyotypic rearrangement that may rovide one explanation for the presence of intermediate repeats in the genomes of diploid organisms and also serve as a model for chromosomal rearrangements in a variety of fungi and other eukaryotes.

\section{RESULTS}

\section{Sizes of the Chromosomes and Sfil Fragments}

An accurate and detailed physical map of chromosome 7 in C. albicans strain 1006 has been constructed (Chibana et al. 1998). This map is based on a genomic library constructed in the fosmid vector; the average size of the $C$. albicans genomic DNA insert in this vector is $\sim 35 \mathrm{kbp}$ (Kim et al. 1992). Chromosome 7 (1 Mbp in size) is the smallest of the eight homologous chromosomes and consists of four SfiI fragments, 7C, 7A, $7 \mathrm{~F}$, and $7 \mathrm{G}$, and two copies of the MRS; the repeats form the borders between SfiI fragments $7 \mathrm{~A}-7 \mathrm{~F}$ and 7F-7G and are oriented in an inverted repeat configuration (Fig. 1a). A fosmid contig composed of the mini-

$\mathbf{a}$

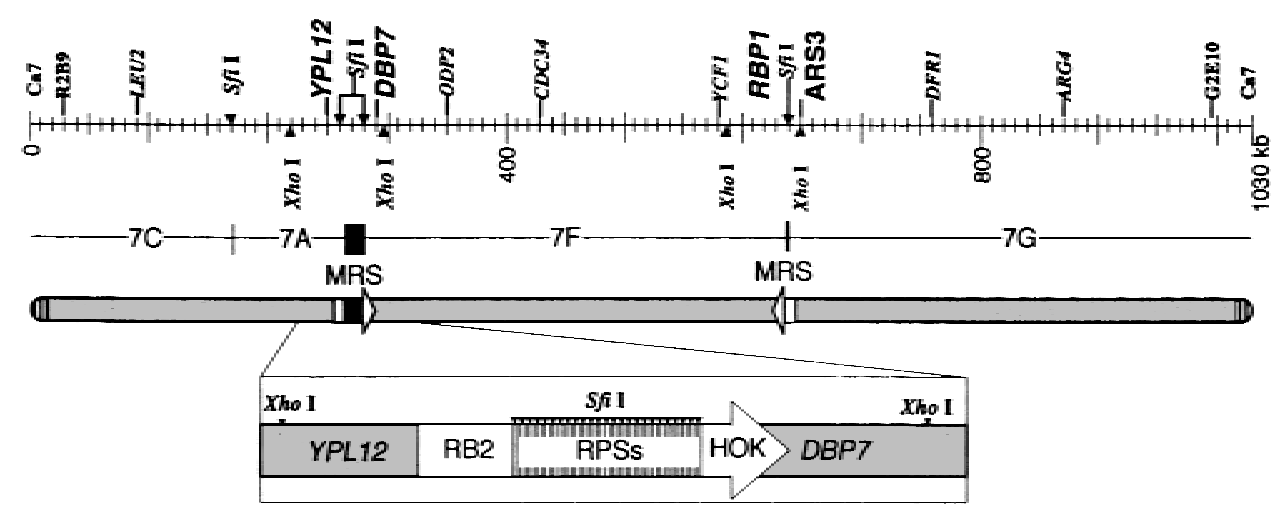

b
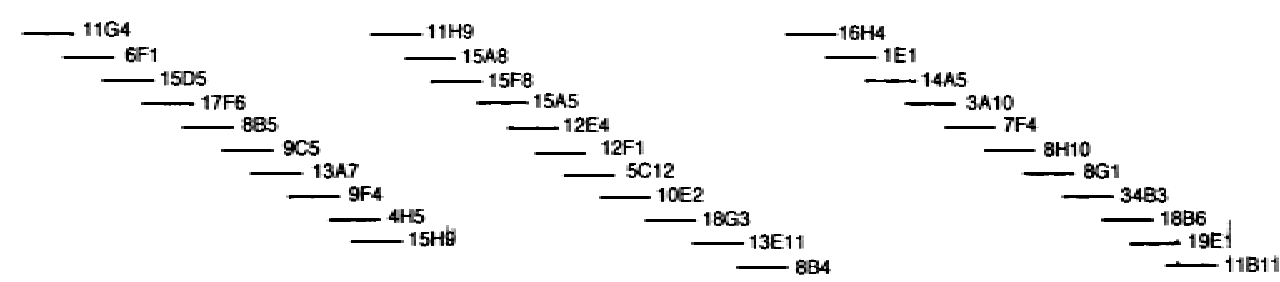

Figure 1 Physical maps of DNA markers on chromosome 7 in Candida albicans strain 1006. DNA markers and restriction maps: The original maps were reported by Chibana et al. (1998). DNA markers used in this study are shown on the top. Fragments 7A, 7F, and 7G are separated by MRSs that include Sfil sites. Fragments 7C and 7A are separated by an Sfil site that is not in an MRS. The two MRSs are inverted and flanking Sfil fragment 7F. Only Xhol sites adjacent to MRS are shown. The MRS region between 7A and 7F was magnified to show the order of subrepeat elements RB2, RPS and HOK (a). Minimal fosmid contig: The minimal contig is composed of the minimum number of fosmids covering the entire chromosome 7. The minimal contig was divided into three contigs, 7C-7A, 7F, and 7G, separated by the two MRS sequences, to identify the distribution of chromosome 7 elements among the different strains. The fosmids from $6 \mathrm{~F} 1$ to $13 \mathrm{~A} 7$ were used as the $7 \mathrm{C}-7 \mathrm{~A}$ contig, those from $15 \mathrm{H} 9$ to $13 \mathrm{E} 11$ as the $7 \mathrm{~F}$ contig, and those from $16 \mathrm{H} 4$ to $34 \mathrm{~B} 3$ as the $7 \mathrm{G}$ contig. Fosmids 11G4, 11B11, 19E1, and 18B6 include subtelomeric repeats 9F4, 4H5, and 8B4 include the MRS (b).

1866 Genome Research

www.genome.org 
mal number of fosmids covering the entire chromosome 7 is shown in Figure 1b. To examine the distribution of all the elements of chromosome 7 in the strains that showed CLP of chromosome 7, the minimal tiling set was divided into three smaller contigs representing the parts of the chromosome separated by MRSs (fragments 7C-7A, 7F, and 7G); these clones were pooled and the pools used as probes for the following experiments: Intact chromosomal DNAs of the strains were separated with CHEF and blotted to membranes. The membranes were hybridized with the three contig probes separately. Several positive bands were found in the strains, ranging in size from $760 \mathrm{kbp}$ to $1,500 \mathrm{kbp}$ (Fig. 2a). This result suggests that the elements of chromosome 7 of 1006 are dispersed among different-sized chromosomes in the other strains. The size of the chromosomes was measured and is shown in Table 1. For convenience the chromosomes containing material found on chromosome 7 in 1006 will temporarily be called chromosome (a), chromosome (b) and chromosome (c) (from largest to smallest in each strain). Names reflecting their origins will be considered in the discussion. The genomic DNAs of the strains were digested with SfiI, run on CHEF gels, and blotted to membranes. The three contig probes were hybridized to the membranes (Fig. 2b). The size of the SfiI fragments that hybridized with the contig probes was measured (Table 1 ). Except for a few bands, the sizes of these fragments are generally conserved across the strains. SfiI fragment 7D in WO-1 is the result of an Sfil RFLP that includes fragment 7C and 7A (Chu et al. 1993). One of the SfiI fragments $7 \mathrm{G}$ in NUM55 was $40 \mathrm{kbp}$ larger than $7 \mathrm{G}$ in 1006. One of the 7A fragments of NUM1000, which is only $40 \mathrm{kbp}$, will be discussed below. These were the only significant polymorphisms found among the $S$ fiI fragments, in clear contrast to the CLP. In addition to the fosmid contigs, DNA markers (LEU2 [7C], CDC34 [7F], ARG4 [7G]; see Fig. 1a) were used as probes for the chromosomes and the SfiI fragments. There was no inconsistency between the results using the individual genes and the fosmid contigs except in NUM1000 (data not shown). The hybridization profiles were most complicated in NUM1000. Although chromosome (c) hybridized to all three fosmid contig probes, its size was only $760 \mathrm{kbp}$. The hybridization signal with the 7C-7A contig was much weaker than with chromosome (b) in NUM1000 (Fig. 2a), and one of the SfiI fragments, 7A, was much smaller than in other strains (Fig. $2 \mathrm{~b}$ and Table 1). This suggests that a chromosomal deletion has occurred. To confirm this hypothesis, chromosome (c) in NUM1000 was eluted from the gel, labeled with $32 \mathrm{P}$, and hybridized to blots of the DNAs of the minimal fosmid contig. The result of this experiment indicates that all of the 7C and half of the 7A fragments were deleted from chromosome (c).
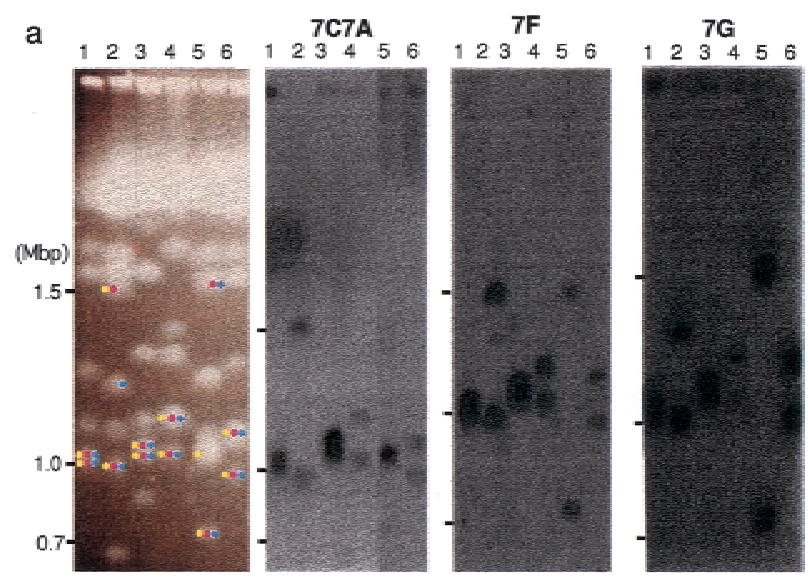

b
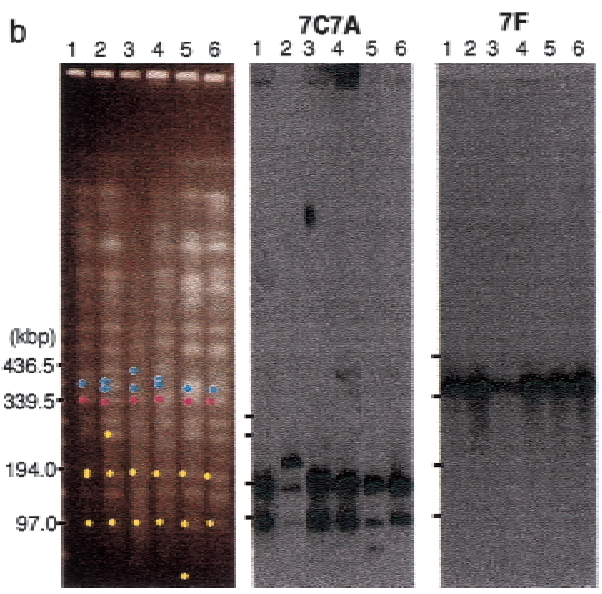

$7 \mathrm{G}$

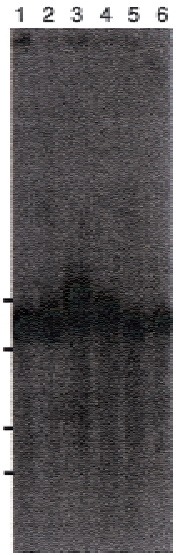

Figure 2 Hybridization of the fosmid contiguous sequence (contig) probes to intact chromosomes and to Sfil fragments. The Southern hybridization profiles with fosmid contig probes $7 \mathrm{C}$ 7A, 7F, and 7G are shown. The gels on the left are marked with colored dots that show which bands correspond to the hybridization profiles on the right. Yellow, red, and blue dots indicate gel bands that hybridize with the 7C-7A, 7F, and $7 \mathrm{G}$ contigs, respectively. Karyotypes of six different strains are shown: lane 1, 1006; lane 2, WO-1; lane 3, NUM55; lane 4, NUM114; lane 5, NUM1000; lane 6, 1719. Hybridization to intact chromosomes: The three bars at the left of each image indicate 1.5 Mbp, 1.0 $\mathrm{Mbp}$, and $0.7 \mathrm{Mbp}$, respectively. The size was estimated with intact chromosomes of Saccharomyces cerevisiae and Lambda ladder DNAs (a). Hybridization to Sfil restriction fragments: The four bars at the left of each image indicate $436.5 \mathrm{kbp}, 339.5$ $\mathrm{kbp}, 194.0 \mathrm{kbp}$, and $97.0 \mathrm{kbp}$, the sizes of Lambda ladder DNAs (b).

\section{MRS Size}

The element within the MRS that is tandemly repeated, RPS, contains several SfiI sites separated by $0.2 \mathrm{kbp}$ to $1.1 \mathrm{kbp}$ (Chibana et al. 1994). Because there may be several copies of RPS and because there are two MRSs on chromosome 7 , it seemed possible that variations in the MRS might contribute significantly to the CLP of chromosome 7 . To measure the size of the gaps between the $S$ fiI fragments $7 \mathrm{~A}-7 \mathrm{~F}$ and $7 \mathrm{~F}-7 \mathrm{G}$, the genomic DNA was digested with the enzyme XhoI, which does not cut in the MRS of chromosome 7 . The fragments 
Table 1. Size of Chromosome 7 and Sfil Fragments

\begin{tabular}{|c|c|c|c|c|c|c|c|c|}
\hline \multirow[b]{2}{*}{ Strain } & \multicolumn{3}{|c|}{ Chromosome 7} & \multicolumn{5}{|c|}{ Sfil fragment (kbp) } \\
\hline & (a) & (b) & (c) & $7 C$ & $7 A$ & 7D* & $7 F$ & $7 G$ \\
\hline 1006 & 1,030 & 1,010 & & 170,180 & 90 & - & 350 & 385 \\
\hline WO-1 & 1,540 & 1,200 & 990 & 170 & 90 & 270 & 340 & 390 \\
\hline NUM55 & 1,060 & 1,030 & & 180 & 90 & - & 350 & 390,430 \\
\hline NUM114 & 1,120 & 1,030 & & 180 & 90 & - & 350 & 390,410 \\
\hline NUM1000 & 1,580 & 1,030 & 760 & 180 & 40,90 & - & 350 & 380 \\
\hline 1719 & 1,080 & 990 & & 180 & 90 & - & 350 & 385 \\
\hline
\end{tabular}

The SFIl fragments were assigned the following probes: 7C: Ca7, 7C7A-contig, R2B9 and LEU2; 7A: 7C7A-contig, YPL12 and RB2; 7F: 7F-contig, DBP7, ODP2, CDC34, YCF1, RBP1 and HOK; 7G: Ca7, 7G-contig, ARS3, DFR1, ARG4, G2E10 and RB2. There is no Sfil site between $7 C$ and $7 A$ in one of the homologous chromosomes in strain WO-1.

were then separated by pulse-field gel electrophoresis, blotted, and probed with markers that map close to the boundaries of the two MRSs in 1006. The size of the fragment that hybridized with the probes gives a measure of the size of the intact MRS. As shown in Figure 1a, YPL12, DBP7, RBP1, and ARS3 are close to the MRSs and hybridized to SfiI fragments 7A, 7F, 7F, and 7G respectively, in all strains. Figure $3 \mathrm{a}$ shows the results with the sequences YPL12 and DBP7. The two probes hybridized to the same band in all strains except NUM1000. The size of each XhoI fragment was measured (Table 2). The genomic DNA was also subjected to double digestion with $\mathrm{XhoI}$ and SfiI, separated by contour-clamped homogeneous electric field (CHEF), and blotted to a membrane that was once again probed with YPL12 and DBP7 (Fig. 3a). To measure the size of gap between the $S$ fiI fragments 7A and 7F, the sizes of XhoI-Sfil fragments were subtracted from the size of XhoI fragment (Table 2). The size of the gap between the $S$ fiI fragments 7F and 7G was calculated in the same way, using the RBP1 and ARS3 probes and is shown in Figure $3 \mathrm{~b}$ and Table 3 . These two probes hybridized to same band in all strains except WO-1.

\section{Location and Orientation of the MRSs}

All the XhoI-digested bands that had been identified with YPL12 and DBP7 were also positive with RB2 and HOK (Fig. 4). These bands hybridized with RPS as well (data not shown). All of the XhoI-SfiI double-digested bands that hybridized to YPL12 were positive with RB2 but not with HOK, while all of the XhoI-Sfil doubledigested bands that were positive with $D B P 7$ were also positive with HOK but not with RB2 (Fig. 4). RPS did not hybridize with any of the bands in the double digests (data not shown). These results show that the DNA markers YPL12, RB2, RPS, HOK, and DBP7 occur in that order at the 7A-7F junction on both homologs in 1006, WO-1, NUM55, NUM114, and 1719 and on one homolog in NUM1000. For the 7F and 7G junction, the same experiment was carried out (Fig. 4), showing that the DNA markers RBP1, HOK, RPS, RB2,
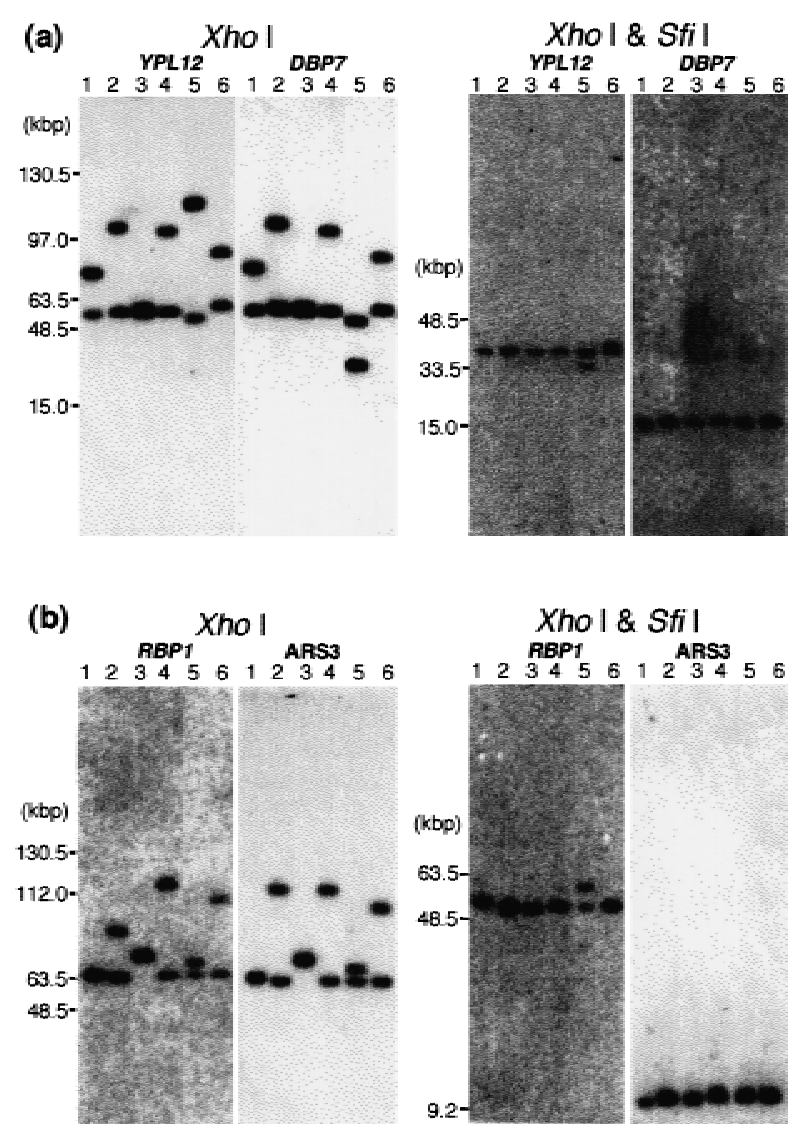

Figure 3 Southern hybridization with probes flanking the MRS to restriction fragments of Xhol and Xhol-Sfil digests. Because the MRSs in chromosome 7 do not include Xhol sites, a Xhol digest leaves fragments including the entire MRS sequences and the adjacent DNA. Four MRS flanking markers, YPL12, DBP7, RBP1, and ARS3 were included in the $X$ hol fragments (Fig. 1). The genomic DNA of each strain was digested with Xhol and with Xhol and Sfil. The DNA was separated by countour-clamped homogeneous electric field and blotted onto a membrane. Lane 1, 1006; lane 2, WO-1; lane 3, NUM55; lane 4, NUM114; lane 5, NUM1000; lane 6, 1719. The DNA size was determined with the MidRange 1 PFG marker (New England Biolabs) and $1 \mathrm{~kb}$ ladder (Bethesda Research Laboratories). The MRS between 7A and 7F: probes YPL12 and DBP7 (a). The MRS between 7F and 7G: probes RBP1 and ARS3 (b). 
Table 2. Measurement of the Gap between Sfil Fragments $7 \mathrm{~A}$ and $7 \mathrm{~F}$

\begin{tabular}{|c|c|c|c|c|c|}
\hline \multirow[b]{2}{*}{ Strain } & \multicolumn{2}{|c|}{ Xhol (kbp) } & \multicolumn{2}{|c|}{ Xhol-Sfil (kbp) } & \multirow{2}{*}{$\begin{array}{c}\text { Gap } \\
\text { (kbp) }\end{array}$} \\
\hline & YPL12 & $D B P 7$ & YPL12 & $D B P 7$ & \\
\hline \multirow[t]{2}{*}{1006} & 80 & 80 & 40 & 16 & 24 \\
\hline & 58 & 58 & 40 & 16 & 2 \\
\hline \multirow[t]{2}{*}{ WO-1 } & 105 & 105 & 40 & 16 & 49 \\
\hline & 59 & 59 & 40 & 16 & 3 \\
\hline \multirow[t]{2}{*}{ NUM55 } & 59 & 59 & 40 & 16 & 3 \\
\hline & 57 & 57 & 40 & 16 & 1 \\
\hline \multirow[t]{2}{*}{ NUM114 } & 101 & 101 & 40 & 16 & 45 \\
\hline & 58 & 58 & 40 & 16 & 2 \\
\hline \multirow[t]{3}{*}{ NUM1000 } & 116 & - & 40 & - & - \\
\hline & 52 & 52 & 34 & 16 & 2 \\
\hline & - & 28 & - & 16 & - \\
\hline \multirow[t]{2}{*}{1719} & 88 & 88 & 43 & 16 & 29 \\
\hline & 59 & 59 & 40 & 16 & 2 \\
\hline
\end{tabular}

The gap between Sfil fragments was measured by subtraction of the total size of the Xhol-Sfil fragment from the size of the $X$ hol fragment. The RPS repeat, which is a subrepeat element of MRS, includes several Sfil sites per unit. Because the size of the unit is $\sim 2 \mathrm{kbp}, 2 \mathrm{kbp}$ corresponds to one RPS unit. Errors of $+/-2 \mathrm{kbp}$ seem to be unavoidable. Because one of the homologous chromosomes has undergone translocation in NUM1000, only one Xhol fragment was assigned to both probes. Each probe hybridized to one other fragment from the translocation.

and ARS3 exist in that order at the 7F-7G junction on both homologs in 1006, NUM55, NUM114, NUM1000, and 1719 and on one homolog of WO-1.

\section{Translocations in WO-1 and NUM1000}

A reciprocal translocation was found between chromosomes 7 and 4 (Chu et al. 1993) in WO-1. To determine the origins of chromosomes (a) and (b) in NUM1000, the bands corresponding to these chromosomes were isolated from a pulse-field gel, labeled, and probed to a blot of the fosmid library. Chromosome (a) hybridized to the fosmids previously assigned to fragments $7 \mathrm{~F}$ and $7 \mathrm{G}$ but not to those from 7C and 7A and also to fosmids from chromosome 4 (data not shown). Chromosome (b) in NUM1000 hybridized to the fosmids of 7C-7A but not those of 7F and 7G and also to fosmids from chromosome 4 (data not shown). This result indicates that chromosomes (a) and (b) contain translocation products of chromosomes 7 and 4 . To investigate whether the translocations in NUM1000 and WO-1 occurred between the MRSs of chromosomes 7 and 4, we looked for MRS-flanking markers on chromosome 4. Using sequence data of the Candida genome project (http://www-sequence.stanford.edu/ group/candida/), DNA markers flanking other MRSs of unknown location in the genome were prepared by PCR. To find DNA markers flanking the MRS of chromosome 4 , whole DNA of chromosome 4 from strain
1006 was labeled and hybridized to the PCR products. We identified four markers from chromosome 4: OGH3 and OGH12, adjacent to HOK, and OGR4 and OGR9, adjacent to RB2 (data not shown). OGH3 hybridized to $S$ fiI fragment $4 \mathrm{~F}$, and OGR9 hybridized to fragment $4 \mathrm{H}$. The sizes of the SfiI fragments of chromosome 4 in WO-1 and NUM1000 are shown in Table 4. To investigate the size of the MRS and the connecting RPS fragments, XhoI-SfiI mapping as in Figure 3 was carried out with OGH3, OGH12, OGR4, and OGR9. In both strains, OGH3 and OGR9 were assigned to the same XhoI band, confirming the connection between $4 \mathrm{~F}$ and $4 \mathrm{H}$, and the size of RPS cluster was determined (Table 5). There are extra XhoI sites between the markers and the MRS on SfiI fragment $4 \mathrm{~N}$, so NgoMI- SfiI mapping rather than XhoI- SfiII mapping was performed to examine the junction of the translocation between chromosomes 4 and 7 in WO-1. RBP1, which is adjacent to HOK on 7F, and OGR4, which is adjacent to RB2 on $4 \mathrm{~N}$, were all assigned to a $235 \mathrm{kbp}$ band (Fig. 5) before digestion with SfiI and were found on separate fragments after. We concluded that the order of markers on this fragment of chromosome (a) is RBP1, HOK, RPS, RB2, and OGR4. Similarly, OGH12, which is adjacent to $\mathrm{HOK}$ on $4 \mathrm{~F}$, and ARS3, which is adjacent to RB2 on 7G, were assigned to the same $285 \mathrm{kbp}$ band (Fig. 5) and were separated after digestion with SfiI I; thus, OGH12, HOK, RPS, RB2, and ARS3, in that order, define the translocation junction of chromosome (b).

In the translocation between chromosomes 4 and 7 in NUM1000 there is an extra XhoI site and an NgoMI

Table 3. Measurement of the Gap between Sfil Fragments $7 \mathrm{~F}$ and $7 \mathrm{G}$

\begin{tabular}{|c|c|c|c|c|c|}
\hline \multirow[b]{2}{*}{ Strain } & \multicolumn{2}{|c|}{ Xhol (kbp) } & \multicolumn{2}{|c|}{ Xhol-Sfil (kbp) } & \multirow{2}{*}{$\begin{array}{l}\text { Gap } \\
\text { (kbp) }\end{array}$} \\
\hline & RBP1 & ARS3 & RBP1 & ARS3 & \\
\hline \multirow[t]{2}{*}{1006} & 64 & 64 & 53 & 9 & 2 \\
\hline & 64 & 64 & 53 & 9 & 2 \\
\hline \multirow[t]{3}{*}{ WO-1 } & - & 118 & - & 9 & - \\
\hline & 91 & - & 52 & - & - \\
\hline & 63 & 63 & 52 & 9 & 2 \\
\hline \multirow[t]{2}{*}{ NUM55 } & 74 & 74 & 52 & 9 & 13 \\
\hline & 74 & 74 & 52 & 9 & 13 \\
\hline \multirow[t]{2}{*}{ NUM114 } & 118 & 118 & 53 & 9 & 56 \\
\hline & 63 & 63 & 53 & 9 & 1 \\
\hline \multirow[t]{2}{*}{ NUM1000 } & 70 & 70 & 60 & 9 & 1 \\
\hline & 63 & 63 & 53 & 9 & 1 \\
\hline \multirow[t]{2}{*}{1719} & 107 & 107 & 53 & 9 & 45 \\
\hline & 63 & 63 & 53 & 9 & 1 \\
\hline
\end{tabular}

The gap was measured by subtraction of the total size of Xhol-Sfil fragment from the size of the Xhol fragment. Because one of the homologous chromosomes has undergone translocation in WO-1, only one Xhol fragment was assigned to both probes. Each probe hybridized to one other fragment from the translocation. 

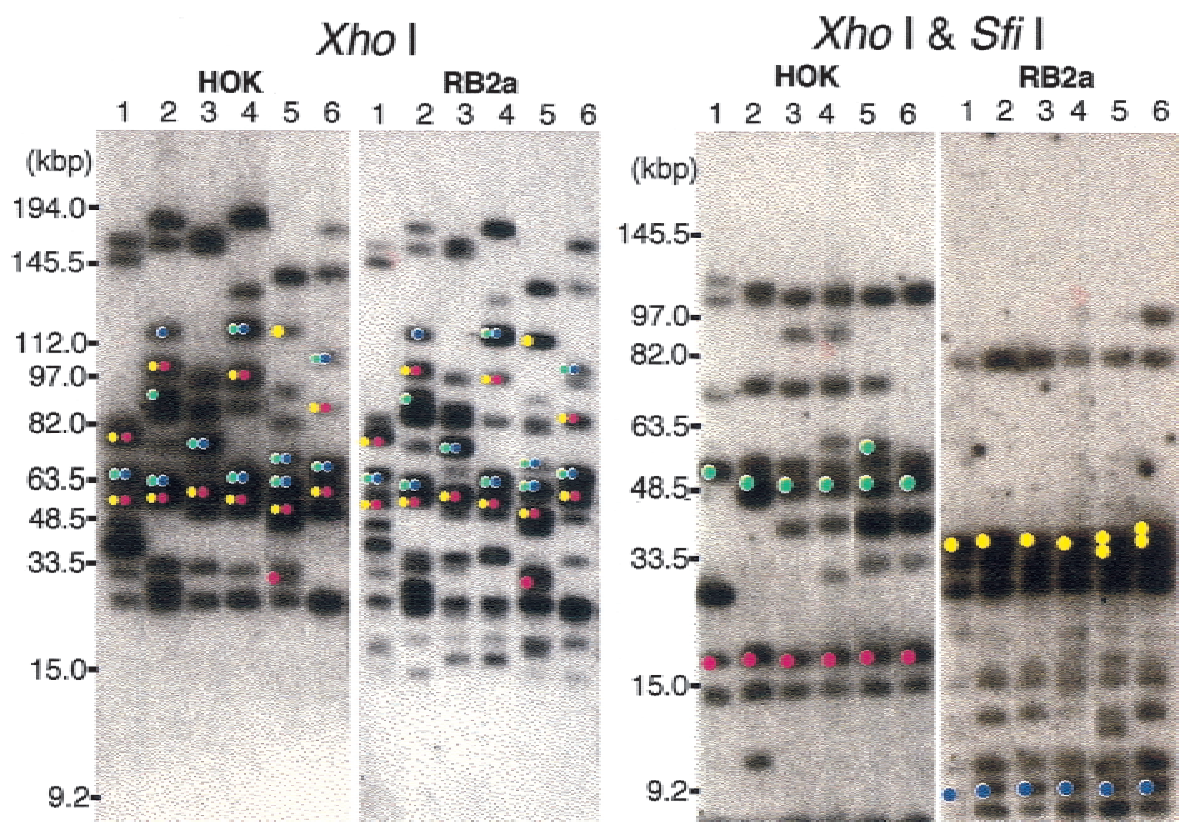

Figure 4 Orientation of the MRS with respect to the flanking markers. The membranes shown in Figure 3 were stripped and rehybridized with RB2a (a part of RB2) and HOK. The bands shown to hybridize to the flanking markers are indicated by colored circles. The bands hybridized to the MRS flanking markers YPL12 (yellow), DBP7 (red), RBP1 (green), and ARS3 (blue) in Figure 3 indicated by dots on the hybridization profiles.

site between the markers, so BssHII-Sfil mapping was performed to examine the junction of the translocation. OGR4, which is adjacent to RB2 on 4E, and DBP7, which is adjacent to HOK on 7F, were assigned to the same 422 kbp-band (Fig. 6) and were separated by SfiI digestion. Thus, markers at the junction of chromosome (a) in NUM1000 are, in order, OGR4, RB2, RPS, HOK, and DBP7. YPL12, which is adjacent to RB2 on $7 \mathrm{~A}$, and OGH12, which is adjacent to $\mathrm{HOK}$ on $4 \mathrm{~F}$, were similarly assigned to a $160 \mathrm{kbp}$ band (Fig. 6) and separated with SfiI. YPL12, RB2, RPS, HOK, and OGH12 are located at the junction of chromosome (b) in NUM1000, in that order.

Table 4. Size of Sfil Fragments of Chromosome 4

\begin{tabular}{lrrrrrrr}
\hline & \multicolumn{6}{c}{ Sfil fragment (kbp) } \\
\cline { 2 - 8 } Strain & $\mathbf{4 0}$ & 4BB & 4N & 4I & 4F2 & 4F & 4H \\
\hline WO-1 & 870 & 33 & 830 & - & - & 380 & 400 \\
NUM1000 & - & 33 & - & 480 & 350 & 380 & 400
\end{tabular}

SFIl fragments were assigned to probes 4O: Ca7, HIS4, 20C4, OGR4 and RB2a; 4BB: Ca7, HIS4 and 20C4; 4N: 20C4, OGR4, and RB2a; 4I: 20C4, 4F2, OGR4; 4F: OGH12, HOK, and OGH3; 4H: RB2a, OGR9, and Ca7. Because there is an additional Sfil site in $4 \mathrm{O}$ in one of the homologous chromosomes of Chromosome 4, 40 of teh homologous chromosome is divided into $4 \mathrm{BB}$ and $4 \mathrm{~N}$ in WO-1 (Chu et al 1993). In NUM1000 a Sfil site was found in $4 \mathrm{~N}$ in both homologous chromosomes; thus, $4 \mathrm{~N}$ is divided into $4 \mathrm{I}$ and $4 \mathrm{~F} 2$ in NUM1000.

\section{Structures of Translocation Products}

We used the information derived from the previous sections to deduce the structure of the translocation chromosomes in WO-1 and NUM1000. Chromosome (a) in WO-1 includes Sfil fragments, 7C, 7A, $7 \mathrm{~F}, 4 \mathrm{~N}$, and $4 \mathrm{BB}$. Because $4 \mathrm{BB}$, which is adjacent to $4 \mathrm{~N}$, hybridized to the telomere sequence, it must be located at one of the ends of the chromosome, arbitrarily written here as the right-hand end. The OGR4 probe is located at the left end of $4 \mathrm{~N}$ and hybridizes with a 235 kbp NgoMI fragment (Fig. 5). The RBP1 probe is at the right end of $7 \mathrm{~F}$ and hybridizes with the $235 \mathrm{kbp}$ NgoMI fragment. The gap between $4 \mathrm{~N}$ and $7 \mathrm{~F}$ is $18 \mathrm{kbp}$. The probe $D B P 7$, which is at the left end of $7 \mathrm{~F}$, and the probe YPL12, which is at the right end of 7A, hybridized with a $105 \mathrm{kbp}$ XhoI fragment. The gap between 7F and 7A is $49 \mathrm{kbp}$ (Table 3). Adjacent to 7C, which includes telomere sequences at the left end, is 7A. Therefore, this chromosome is composed of fragments 7C (170 kbp)-7A (90 kbp)-RPS (49kbp)-7F (340 kbp)-RPS (18 kbp)-4N (830 kbp)-4BB (33 kbp) (Table 6). The total calculated size is 1,530 $\mathrm{kbp}$, close to the measured size of chromosome (a), $1,540 \mathrm{kbp}$. The same analysis was applied to other chromosomes and other strains. A summary of the structures of the chromosomes containing part or all of chromosome 7 is shown in Table 6.

\section{Aneuploidy of Chromosome (b) in NUM1000}

Although chromosome (b) has SfiI fragments in common with chromosomes 4, and (c) in NUM1000 (Fig.

Table 5. Measure of the Gap between Sfil Fragments $4 \mathrm{~F}$ and $4 \mathrm{H}$

\begin{tabular}{lcccccc}
\hline & \multicolumn{2}{c}{ Xhol (kbp) } & & \multicolumn{2}{c}{ Xhol-Sfil (kbp) } & \\
\cline { 2 - 3 } Strain & OGH3 & OGR9 & & OGH3 & OGR9 & $\begin{array}{c}\text { Gap } \\
\text { (kbp) }\end{array}$ \\
\hline \multirow{2}{*}{ WO-1 } & 64 & 64 & & 48 & 8 & 8 \\
NUM1000 & 64 & 64 & & 48 & 8 & 8 \\
& 64 & 64 & & 49 & 8 & 7 \\
& 56 & 56 & & 43 & 8 & 5 \\
\hline
\end{tabular}

The gap was measured by subtraction of the total size of the Xhol-Sfil fragment from the size of the Xhol fragment. 
(a)
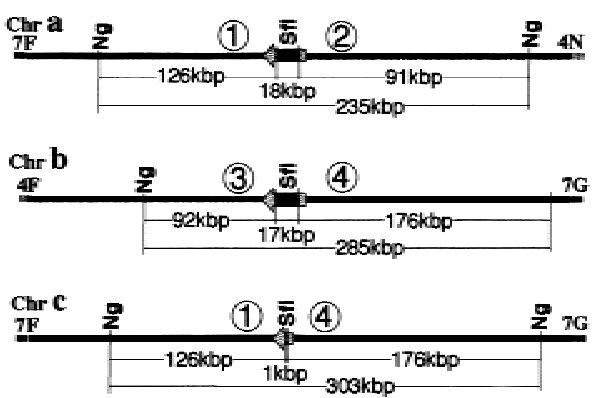

(b)

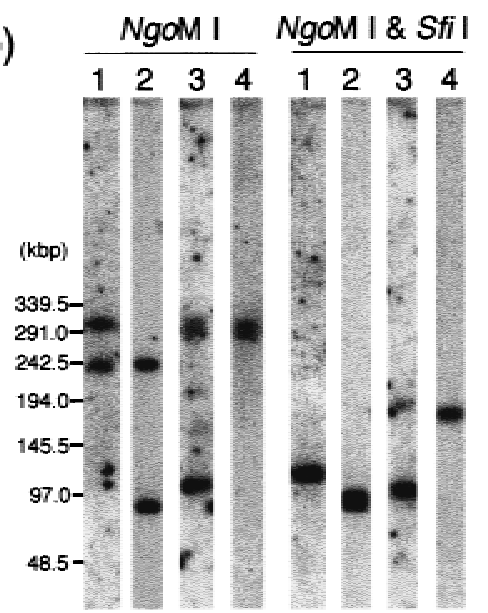

Figure 5 Junction of the translocation between chromosomes 4 and 7 in WO-1. NgoMl and Sfil restriction map of the junction (a). The locations of the MRS flanking markers are indicated by numbers in circles: (1) RBP1; (2) OGR4; (3) OGH12; and (4) ARS3. The locations of RBP1 and ARS 3 in chromosome 7 are shown in Figure 1. OGR4 and OGH12 were assigned to Sfil fragments $4 \mathrm{~N}$ and $4 \mathrm{~F}$ of chromosome 4, respectively (not shown). Southern hybridization with markers flanking the MRSs of chromosomes 4 and 7 (b). Genomic DNA of WO-1 was digested with NgoMl and with $\mathrm{NgoMI}$ and Sfil and resolved as described in Methods. The fragments were then transferred onto membranes and hybridized with RBP1, lane 1; OGR4, lane 2; OGH12, lane 3; and ARS3, lane 4. OGH12 shows weak cross-hybridizaton to 7F. The DNA size was determined by Lambda ladder DNA markers.

7)7, the probes assigned to chromosome (b) always hybridized with a higher intensity to this band than to other chromosomes. For this reason, we investigated the ploidy of chromosome (b) in NUM1000. The strength of the signal with the probes OGH12 and OGH9 on chromosome (b) is about twice that of chromosome 4, which is monosomic (Fig. 7). Probe YPL12 hybridizes to chromosome (b) with an intensity approximately twofold that of chromosome (c), which is monosomic. The signals on chromosomes (a) and (c) with DBP7 and ARS3 are very similar. These results indicate that chromosome (b) is disomic, so 7C and part of 7A are disomic, and the telomereproximal part of $7 \mathrm{~A}$ and all of $4 \mathrm{~F}$ and $4 \mathrm{H}$ are trisomic in NUM1000.

\section{Correspondence between the Calculated Size} of the MRS and Intensity of Hybridization of RPS

The sizes of the RPS clusters in the two MRSs in chromosome (a) in 1719 and the NUM114 were $74 \mathrm{kbp}$ and $101 \mathrm{kbp}$. On the other hand, the total size of the RPS cluster is only $1 \mathrm{kbp}$ on chromosome (a) in NUM1000 (Table 6). To confirm that the size of the RPS cluster calculated from the restriction mapping results reflects the number of RPSs, we hybridized Southern blots of pulse-field chromosome separations with an RPS probe (Fig. 8). The intensities of hybridization of the chromosome 7 homologs and chromosome 7-related chromosomes (Fig. 8, indicated by arrowheads) were corre-
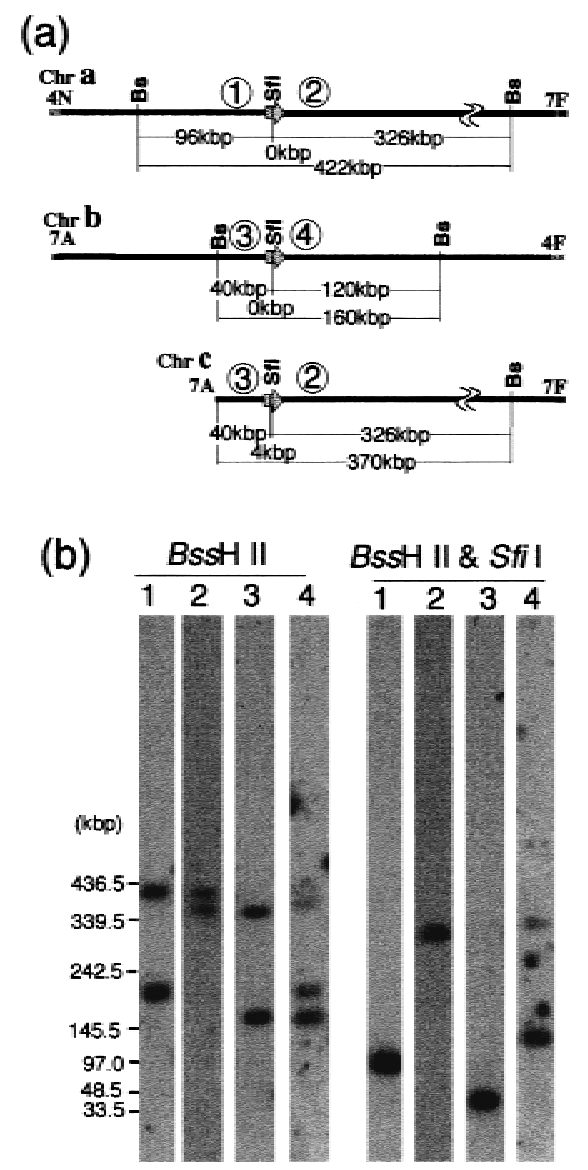

Figure 6 Junction of the translocation between chromosomes 4 and 7 in NUM1000. BssHII and Sfil restriction maps of the junction (a). The locations of the MRS flanking markers are indicated by numbers in circles: (1) OGR4; (2) DBP7; (3) YPL12; and (4) OGH12. The locations of YPL12 and DPB7 in chromosome 7 are shown in Figure 1. OGR4 and OGH12 were assigned to Sfil fragments $4 \mathrm{~N}$ and $4 \mathrm{~F}$ of chromosome 4, respectively (not shown). Southern hybridization with MRS flanking markers of chromosomes 4 and 7 (b). Genomic DNA of WO-1 was digested with BssHII and with BssHII and Sfil. The restriction fragments were separated by contour-clamped homogeneous electric field. The fragments were then transferred onto membranes and hybridized with OGR4, lane 1; DBP7, lane 2; YPL12, lane 3; and $\mathrm{OGH} 12$, lane 4 . The DNA size was determined by Lambda ladder DNA markers. 
Chibana et al.

Table 6. Total Size of the Sfil Fragments and Gaps

\begin{tabular}{|c|c|c|c|c|c|}
\hline Strain & Chr. 7 & Sfil elements \& MRS (M) & Sfil total & Gap total & Sum total \\
\hline \multirow[t]{2}{*}{1006} & a & 7C-7A-M-7F-M-7G & 1000 or 1010 & 26 & 1026 or 1036 \\
\hline & b & 7C-7A-M-7F-M-7G & 1000 or 1010 & 4 & 1004 or 1014 \\
\hline \multirow[t]{3}{*}{ WO-1 } & a & 7C-7A-M-7F-M-4N-4BB & 1463 & 67 & 1530 \\
\hline & b & $4 \mathrm{H}-\mathrm{M}-4 \mathrm{~F}-\mathrm{M}-7 \mathrm{G}$ & 1170 & 25 & 1195 \\
\hline & c & 7D-M-7F-M-7G & 1000 & 3 & 1003 \\
\hline \multirow[t]{2}{*}{ NUM55 } & a & 7C-7A-M-7F-M-7G & 1050 & 14 or 16 & 1064 or 1066 \\
\hline & b & 7C-7A-M-7F-M-7G & 1010 & 14 or 16 & 1024 or 1026 \\
\hline \multirow[t]{2}{*}{ NUM114 } & a & 7C-7A-M-7F-M-7G & 1010 or 1030 & 101 & 1111 or 1131 \\
\hline & b & 7C-7A-M-7F-M-7G & 1010 or 1030 & 3 & 1013 or 1033 \\
\hline \multirow[t]{3}{*}{ NUM1000 } & a & $4 B B-4 N(4 I+4 E)-M-7 F-M-7 G$ & 1593 & 1 & 1594 \\
\hline & b & 7C-7A-M-4F-M-4H & 1050 & 5 or 7 & 1055 or 1057 \\
\hline & c & d7A-M-7F-M-7G & 770 & 3 & 773 \\
\hline \multirow[t]{2}{*}{1719} & a & 7C-7A-M-7F-M-7G & 1000 & 74 & 1074 \\
\hline & b & 7C-7A-M-7F-M-7G & 1000 & 3 & 1003 \\
\hline
\end{tabular}

The chromosomes were composed of the Sfil elements and MRSs. The size of each Sfil fragment is shown in Tables 1 and 4 . The total size of the Sfil fragments is shown as Sfil total. The sizes of the gaps shown in Table 2, 3 and 5 and Figures 5 and 6 were totalled in each homologous chromosome and are shown as gap total. The gap size is approximately, but not exactly, the size of the RPS. To reconcile the total sizes of the Sfil fragments and gaps to the chromosome size, the appropriate gap sizes were chosen.

lated with the calculated size of the RPS cluster. In NUM114 and 1719 the intensity of chromosome (a) was much higher than the intensity of chromosome (b), indicating that two large MRSs exist on chromosome (a).

\section{DISCUSSION}

Much effort has been expended to understand the nature of the genome and its apparent plasticity in $C$. albicans. In this study, we analyzed the physical basis of the size variation of chromosome 7 in six strains that show significant polymorphism of this chromosome. We show here that the great majority of changes involve the MRS; this result suggests that this intermediate repeat may play a leading role in the production of karyotypic variability in C. albicans, including both

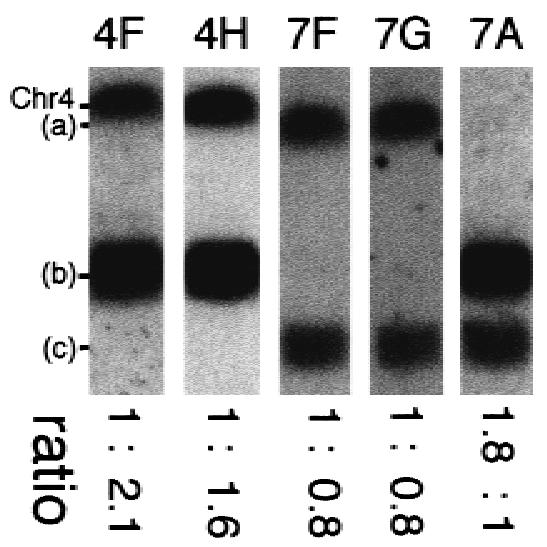

Figure 7 Aneuploidy of chromosome (b) in NUM1000. The chromosomal DNAs of NUM1000 were separated and transferred onto a membrane. The membrane was hybridized to OGH12, OGR9, DBP7, ARS3 and YPL12, and markers were assigned to $4 \mathrm{~F}, 4 \mathrm{H}, 7 \mathrm{~F}, 7 \mathrm{G}$, and $7 \mathrm{~A}$ respectively. The numbers at the bottom show the intensity ratios. size variation of intact homologs and translocations involving nonhomologous chromosome. The mechanism of translocation we propose involves crossing over between nonhomologous chromosomes due to pairing at the homologous region of itself on different chromosomes. Such a model makes some testable predictions. The strongest prediction is that the directionality of the MRS dictates allowed translocation products (Fig. 9). That is, translocation can only occur between fragments on opposite ends of the repeat. Thus, we would not expect a fragment on the RB2 side of the MRS to end up in a translocation with another frag-

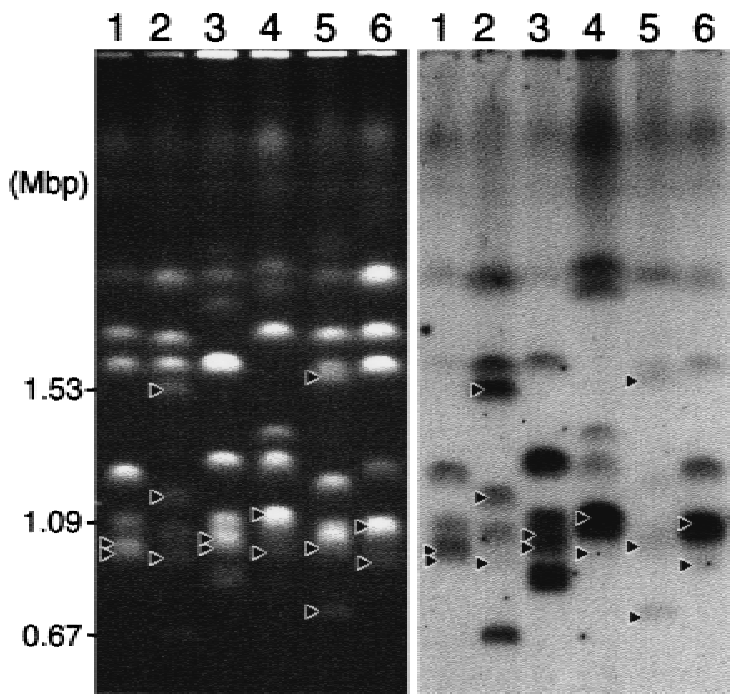

Figure 9 Schematic representation of the chromosomes. Telomeric and subtelomeric regions are shown by vertical stripes on the ends. The colored boxes indicate 7C7A (yellow), 7F (pink), and 7G (blue). Green boxes indicates translocated Sfil fragments of chromosome 4. Red arrows represent the sizes and orientation of the MRSs, in the order (head to tail) of HOK, RPS, and RB2. 


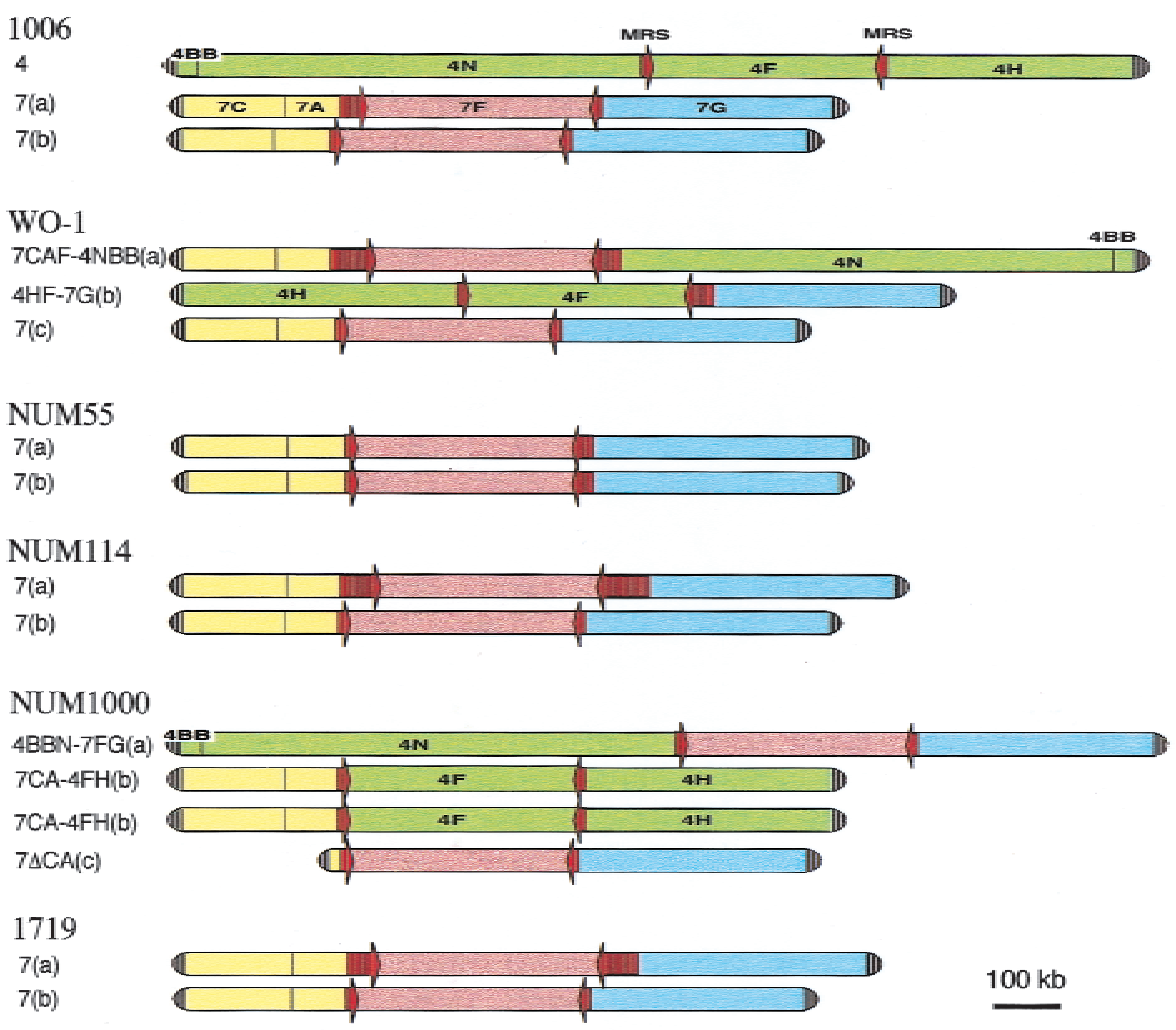

Figure 8 Hybridization of chromosomes with the RPS probe. Lane 1, 1006; lane 2, WO-1; lane 3, NUM55; lane 4, NUM114; lane 5, NUM1000; lane 6, 1719. Arrowheads indicate chromosomes (a), (b), and (c) in each lane. Lane 1, 1006; lane 2, WO-1; lane 3, NUM55; lane 4, NUM114; lane 5, NUM1000; lane 6, 1719.

ment at that side. Figure 9 shows that the translocations we have studied have been the result of permitted recombination events. The second prediction is that translocation should be rare or nonexistent at SfiI sites that do not involve the MRS. This prediction is weaker because it can only be supported by absence of data. However, in the cases studied here, both these predictions are fulfilled.

\section{MRS Mediates Translocations}

The MRS, which includes the sequence elements HOK, RPS, and RB2, in that order (Chibana et al. 1998; Chindamporn et al. 1998), is located on seven of the eight chromosomes; only RB2 is found on chromosome 3 (Chindamporn et al. 1998). RPS includes several SfiI sites (Iwaguchi et al. 1992a; Chibana et al. 1994). The two MRSs on chromosome 7 in 1006 are inverted and flank the $350 \mathrm{kbp}$ S fiI fragment, 7F (Chibana et al. 1998). Chu et al. (1993) reported a reciprocal translocation of SfiI fragments between chromosomes 7 and 4 in WO-1. In this study, a similar but not identical translocation was found in NUM1000. The reciprocal translocation in WO-1 occurred by recombination between the MRS at $4 \mathrm{~F}-4 \mathrm{~N}$ and that at 7F-7G. The translocation in NUM1000 occurred at the MRSs at 4F-4N and 7A-7F. Iwaguchi et al. (2000) found a strain that has an extra chromosome composed of SfiI fragments, $4 \mathrm{H}, 7 \mathrm{~F}$, and $7 \mathrm{G}$. We found that the MRS occurs between $4 \mathrm{~F}$ and $4 \mathrm{H}$ on chromosome 4 and that a reciprocal translocation between the MRS at 7A-7F and the MRS at $4 \mathrm{~F}-4 \mathrm{H}$ most likely occurred. Navarro-Garcia et al. (1995) reported a reciprocal translocation of SfiI fragment $7 \mathrm{G}$ and $2 \mathrm{~A}$. A translocation between MRS of $7 F-7 G$ and of $2 \mathrm{U}-2 \mathrm{~A}$ is proposed to have led to that chromosome. Chromosome 2 is composed of Sfil fragments $2 \mathrm{U}$ and $2 \mathrm{~A}$ (Chu et al. 1993). This suggests that an MRS exists between these two elements, which was found $(\mathrm{H}$. Chibana, in prep.). It seems likely that any MRS region is a potential site for translocations.

\section{Conservation of Synteny in \\ Fragments Bounded by the MRS}

Although some polymorphisms independent of the MRS were found in the strains studied here, the size of the SfiI fragments was mostly conserved. Iwaguchi et al. (1992a) reported that among fifty clinical isolates, the size of chromosome 3 , which lacks HOK and RPS, was the most conserved. Our data, together with that observation, suggest that translocation is mediated by the MRS in the most cases. Thus, we propose that C. albicans translocation chromosomes be named to reflect Sfil synteny. Chromosomes in which no translocation is found, such as chromosome 7 in 1006, NUM55, NUM114, and 1719, would be called chromosome 7 as before. To distinguish homologous chromosomes of differing sizes, the larger one would be chromosome $7 \mathrm{a}$ and the smaller 7b. In WO-1, we call chromosome (a) chromosome 7CAF-4NBB, chromosome (b) is chromosome 4HF-7G, and chromosome (c) is chromosome 7. In NUM1000, chromosome (a) is designated Chromosome 4BBN$7 \mathrm{FG}$, chromosome (b) is chromosome 7CA-4FH, and chromosome (c) is chromosome 7DCA (Fig. 9).

\section{MRS Mediates Chromosome-Length Polymorphism Not Involving Translocations}

CLP due to change in the number of rDNA repeats has been reported in C. albicans (Iwaguchi et al. 1992b; 
Rustchenko et al. 1993). Variation in the number of repeats is a common feature of tandemly repeated DNA, as we have shown with the RPS element here. The MRS includes a subunit, RPS, that is tandemly repeated (Iwaguchi et al. 1992a). We have observed that changes in the number of copies of RPS can change the size of a chromosome homolog in several of the strains. The sizes of the RPS clusters in the two MRSs in one of the homologs of chromosome 7 in 1006, 1719, and NUM114 were $26 \mathrm{kbp}, 74 \mathrm{kbp}$, and $101 \mathrm{kbp}$ and the sizes of the chromosomes were $1030 \mathrm{kbp}, 1080$ $\mathrm{kbp}$, and $1120 \mathrm{kbp}$, respectively (Table 6). In NUM114, about $10 \%$ of chromosome $7 \mathrm{a}$ is composed of the MRSs, including several tandem repeats of RPS.

\section{Chromosome-Size Polymorphisms Not Involving the MRS}

Chu et al. (1993) reported that C. albicans strains WO-1 and 1006, which have different karyotypes, show highly conserved SfiI restriction maps. In this study, the sizes of the SfiI fragments of chromosome 7 were mostly conserved in the six strains studied, although they possess widely different sizes of chromosome 7 . An exception occurred in NUM1000, in which chromosome 7c has lost all of fragment 7C and two-thirds of fragment 7A. Size polymorphisms of less than 10 $\mathrm{kbp}$ are found more often in SfiI fragments $7 \mathrm{C}$ and $7 \mathrm{G}$, which are telomeric, than in the $7 \mathrm{~A}$ and $7 \mathrm{~F}$ fragments (Table 1). In NUM55, one of the 7G fragments is $40 \mathrm{kbp}$ larger than 7G in 1006 (Table 1). There was no evidence of translocation in this SfII fragment. McEachern and Hicks (1993) reported telomere-length polymorphism in C. albicans. Louis (1994) reported polymorphism in the subtelomeric regions in Saccharomyces cerevisiae. Care2 (Lasker et al. 1992) and Rel-2 (ThrashBingham and Gorman 1993), which are repeated genomic elements, were assigned to the subtelomeric regions on chromosome 7 fragments $\mathrm{C}$ and $\mathrm{G}$ of strain 1006 (Chibana et al. 1998). Thus, one possible reason for the size variation of these fragments in other strains is length polymorphism in the telomere or in subtelomeric repeats. An alternative mechanism for length polymorphism of the SfiI fragments is the insertion or excision of transposons. Goodwin and Poulter (2000) have examined the emerging sequence of the $C$. albicans genome and have found evidence for more than 350 transposon insertions. Variations in gene size have been attributed to the excision of retrotransposons 1006 and CAI-4 (J.L. Beckerman, H. Chibana, J. Turner, and P.T. Magee, in prep.), and their presence or absence would affect chromosome size in unrelated strains.

\section{Natural Aneuploidy in Candida albicans}

Aneuploid strains of C. albicans have been reported since the early 1980s (Whelan and Magee 1981). If a strain has lost one homolog of a chromosome, it grows slowly (Barton and Gull 1992; Magee and Magee 1997; Janbon et al. 1998). Janbon et al. (1998) found that selection for growth on L-sorbose resulted in loss of one homolog of chromosome 5. Growth on glucose selects for strains that have two copies of the remaining homolog. The same group later showed that the loss of one homolog of chromosome 4 is associated with resistance to fluconazole in one Candida strain (Perepnikhatka et al. 1999). It is possible that there are other conditions that select strains that have undergone chromosome nondisjunction. One of these unknown conditions may have selected NUM1000, which has undergone nondisjunction of a translocation chromosome, chromosome 7A-4F.

\section{Molecular Basis of Genome Fingerprinting with Ca3, 27A, and RPS}

Ca3 (Sadhu et al. 1991), 27A (Scherer and Stevens 1988), and RPS (Iwaguchi et al. 1992a) probes have been used as tools for epidemiological analysis of $C$. albicans infections. When genomic Southern blots of various strains are probed with any of these sequences, restriction fragment-length polymorphisms are found (Pujol et al. 1997). Ca3, 27A, and RPS are included in the MRS, and all share some common sequences (Chindamporn et al. 1998; Chibana et al. 1998). What is the basis of the variation revealed by these probes? A major cause is the diversity in the size of RPS unit due to the number of short periodic internal repeats in found in different strains (Chibana et al. 1994; Doi et al. 1998). A second reason is heterogeneity in sites for the restriction enzyme EcoRI. Sites for this enzyme, which is used in many epidemiological studies, are not highly conserved in the RPS family (Chibana et al. 1994), so that EcoRI cuts the whole RPS cluster out occasionally. As shown in Figures 8 and 9, the number of RPSs varies among MRSs, chromosomes, and strains. The combination of all these factors leads to different profiles of hybridization with Ca3, 27A, and RPS. Sister chromatid exchange and interchromosomal gene conversion presumably operate to change the number of RPS repeats and the specific sequence of some of the RPSs at MRSs (Pujol et al. 1999). These changes result in the diversity in the Southern-hybridization profiles of strains as they diverge from a common ancestor. The results of this study show that the genome of $C$. albicans is unique among the fungi so far analyzed. Its linkage unit is not a full chromosome, as is the case with the great majority of eukaryotes; instead the genome is constructed of gene clusters bound by a complex intermediate repeat, the MRS. Conservation among strains is at the level of these clusters, which rearrange at a relatively high frequency to yield karyotypes that, although usually diploid in gene content, do not contain pairs of identical homologs. 
The organism that seems to lack a sexual cycle but is able to adapt to a variety of niches, as shown by its normally commensal but sometimes parasitic lifestyle, C. albicans must have mechanisms to provide genetic variation. Chromosome rearrangement has been proposed as one such mechanism (Rustchenko-Bulgac et al. 1990; Chu et al. 1993), and this study provides both the evidence for this rearrangement and a proposed mechanism. Lacking is the demonstration that the rearrangements we describe here affect gene expression. The imminent completion of the physical map (Chibana et al. 1998) and of the sequence (http://wwwsequence.stanford.edu/group/candida/) will provide the information necessary to investigate differences in gene regulation related to chromosome rearrangement.

\section{METHODS}

\section{Strains}

The 1006 strain (Goshorn and Scherer 1989) has been used as standard for chromosome analysis in C. albicans. This strain was chosen because it possesses eight pairs of homologous chromosomes, each pair of homologs almost identical in size except for chromosome R (Chu et al. 1993). The electrophoretic karyotype of 1006 is the one most frequently found in clinical isolates. WO-1 (Slutsky et al. 1985) was shown by Chu et al. (1993) to have several reciprocal translocations, including one involving chromosome 7. Iwaguchi et al. (1990) selected ten strains showing chromosome length polymorphism (CLP) from 50 clinical strains in Nagoya, Japan. Of the ten strains, three-NUM55, NUM114, and NUM1000, all of which showed CLP in chromosome 7-were chosen for this study. The 1719 was chosen from five clinical isolates in the Scherer strain collection (http://alces.med.umn.edu/Candida/ strainlist) because it also showed CLP in chromosome 7 .

\section{Polymerase Chain Reaction (PCR)}

Oligo DNAs, shown below, were synthesized and used for PCR amplification of the DNA markers:

HIS4, 5'CCTCAGTCACAATAAGGACTGGACGAT3' and 5'CGGGGTGAGATTGGCTGATATTGAGAA3' ; OGH3 , 5'CCCACTTAATTTCCCACATCCAGTTACTT3' and 5'CGG TAACCATTTGTTAAAAACAATTGTATC3'; OGH12, 5'AATC TAGCCCGATGTGGAAAACCAT3' and 5'CACATCACCAACT TAGCACCTTCATT3'; OGR4, 5'TTGTAAACTGTGAATTG CAGTTGATGAGTT3' and 5'GTCATAGTAGTAATATGA TGTGTGGCGTGC3'; OGR9, 5'AGAAGGAGGTACACAATG GACCATT3' and 5'CTAAGGAACCACGAGGGTGAAAGTA3'; RBP1，5'GCATCGTGGGGATACTAACTAACTAC3' and 5'TG CAGCTATATATCGAGGTTTTAGTTCAAC3'. PCR products were amplified with each primer pair. All PCR was carried out under the following conditions: Step $1,94^{\circ} \mathrm{C}$ for $3 \mathrm{~min}$; step 2, $94^{\circ} \mathrm{C}$ for $30 \mathrm{sec}$; step $3,55^{\circ} \mathrm{C}$ for $30 \mathrm{sec}$; step $4,70^{\circ} \mathrm{C}$ for $1 \mathrm{~min}$; step 5 , repeat step 2 , thirty times; step $6,68^{\circ} \mathrm{C}$ for $10 \mathrm{~min}$ with $2.5 \mathrm{M} \mathrm{MgCl} 2$.

\section{DNA Probes and Labeling}

All probes used in this study are shown in Figure 1. Preparation of fosmid DNA and whole-chromosome DNA was described by Chibana et al. (1998). PCR products and restriction fragments were purified by agarose gel electrophoresis (Heery et al. 1990). The isolated DNA was labeled with 32P-dCTP using the RediPrime kit (Amersham).

\section{Southern Blots and Hybridization}

The chromosomal DNAs separated by pulse-field electrophoresis were transferred onto Hybond- $\mathrm{N}^{+}$membrane (Amersham). Hybridization to the probes was carried out with $50 \%$ $(\mathrm{v} / \mathrm{v})$ formamide, $6 \mathrm{x}$ SSPE, $5 \mathrm{x}$ Denhardt's solution and $0.5 \%$ of SDS at $42^{\circ} \mathrm{C}$ for overnight. The membrane was washed twice with $2 \times$ SSPE and $0.5 \%$ SDS at room temperature for $15 \mathrm{~min}$ and once with $0.1 \mathrm{x}$ SSPE and $0.5 \%$ SDS at $65^{\circ} \mathrm{C}$ for $30 \mathrm{~min}$.

\section{Pulse-Field Separations}

DNA preparation for pulse-field gels essentially was as described by Chu et al. (1993). Separation of chromosomes was carried out at $15^{\circ} \mathrm{C}$ in $0.5 \mathrm{X}$ TBE $(44.5 \mathrm{mM}$ Tris, $44.5 \mathrm{mM}$ Boric acid, $1 \mathrm{mM}$ EDTA) on a BioRad CHEF (contour-clamped homologous electric field) DRIII instrument. Chromosome size between $1.1 \mathrm{Mbp}$ and 1.6 Mbp was estimated using chromosomal DNA of $S$. cerevisiae (Bio Rad). Lambda ladder PFG Markers (New England Biolabs) were used as size markers in the 50-kbp-1,100-kbp range, Mid Range DNA size markers (NEB) for $15 \mathrm{kbp}$ to $400 \mathrm{kbp}$, and a 1-kb ladder (BRL) in the 12-kbp-and-below range. The conditions for separation are as follows: (Fig. 2a) $0.9 \%$ agarose gel, $80 \mathrm{sec}$ to $130 \mathrm{sec}, 5 \mathrm{~V} / \mathrm{cm}$, $120^{\circ}$ included angle for $24 \mathrm{~h}, 150 \mathrm{sec}$ to $300 \mathrm{sec}, 4.5 \mathrm{~V} / \mathrm{cm}$, $120^{\circ}$ for $16 \mathrm{~h}$, and then $720 \mathrm{sec}$ to $900 \mathrm{sec}, 2.0 \mathrm{~V} / \mathrm{cm}, 106^{\circ}$ for $24 \mathrm{~h}$. (Fig. 2b) $0.9 \%$ agarose, $7 \mathrm{sec}$ to $100 \mathrm{sec}, 4.5 \mathrm{~V} / \mathrm{cm}, 120^{\circ}$ for $24 \mathrm{~h}$, and then $80 \mathrm{sec}$ to $400 \mathrm{sec}, 3.5 \mathrm{~V} / \mathrm{cm}, 120^{\circ}$ for $24 \mathrm{~h}$. (Fig. 3a) $0.9 \%$ agarose gel, $6.0 \mathrm{~V} / \mathrm{cm}, 120^{\circ}$ for $14 \mathrm{~h}$, and then $8 \mathrm{sec}$ to $30 \mathrm{sec}, 5 \mathrm{~V} / \mathrm{cm}, 120^{\circ}$ for $6 \mathrm{~h}$. (Fig. $\left.3 \mathrm{~b}\right) 0.9 \%$ agarose gel, $0.5 \mathrm{sec}$ to $4 \mathrm{sec}, 6.0 \mathrm{~V} / \mathrm{cm}, 120^{\circ}$ for $14 \mathrm{~h}$, and followed by $3 \mathrm{sec}$ to $20 \mathrm{sec}, 4 \mathrm{~V} / \mathrm{cm}, 120^{\circ}$ for $5 \mathrm{~h}$. (Fig. 5) $0.9 \%$ agarose, $5 \mathrm{sec}$ to $30 \mathrm{sec}, 6 \mathrm{~V} / \mathrm{cm}, 120^{\circ}$ for $14 \mathrm{~h}$, and followed by $30 \mathrm{sec}$ to $80 \mathrm{sec}$, $5 \mathrm{~V} / \mathrm{cm}, 120^{\circ}$ for $8 \mathrm{~h}$. (Fig. 6) $0.9 \%$ agarose, $7 \mathrm{sec}$ to $100 \mathrm{sec}, 4.5$ $\mathrm{V} / \mathrm{cm}, 120^{\circ}$ for $24 \mathrm{~h}$, and then $80 \mathrm{sec}$ to $400 \mathrm{sec}, 3.5 \mathrm{~V} / \mathrm{cm}$, $120^{\circ}$, for $12 \mathrm{~h}$. (Fig. 8) $0.7 \%$ agarose III (Amresco), $70 \mathrm{sec}$ to $100 \mathrm{sec}, 5 \mathrm{~V} / \mathrm{cm}, 120^{\circ}$ for $12 \mathrm{hr}, 100 \mathrm{sec}$ to $300 \mathrm{sec}, 4.5 \mathrm{~V} / \mathrm{cm}$, $120^{\circ}$ for $26 \mathrm{~h}$, and then $720 \mathrm{sec}$ to $900 \mathrm{sec}, 2.0 \mathrm{~V} / \mathrm{cm}, 106^{\circ}$ for $16 \mathrm{~h}$.

\section{Densitometry}

The densitometry of each bands of Figure 7 was performed with the program NIH Image. The ratio of bands on each lane was calculated after subtraction of the background which was measured on each lane.

\section{ACKNOWLEDGMENTS}

We thank Ikuyo Mizuguchi for sending strains NUM55, NUM114, NUM1000, and the rest of the NUM series and Suzanne Grindle for strain 1719. This work was supported by Grants No. AI16567 and AI35109 from the National Institute of Allergy and Infectious Diseases.

The publication costs of this article were defrayed in part by payment of page charges. This article must therefore be hereby marked "advertisement" in accordance with 18 USC section 1734 solely to indicate this fact.

\section{REFERENCES}

Asakura, K., Iwaguchi, S., Homma, M., Sukai, T., Higashide, K., and

Tanaka, K. 1991. Electrophoretic karyotypes of clinically isolated 
yeasts of Candida albicans and C. glabrata. J. Gen. Microbiol. 137: 2531-2538.

Barton, R.C. and Gull, K. 1992. Isolation, characterization, and genetic analysis of monosomic aneuploid mutants of Candida albicans. Mol. Microbiol. 6: 171-177.

Chibana, H., Iwaguchi, S., Homma, M., Chindamporn, A., Nakagawa, Y., and Tanaka, K. 1994. Diversity of tandemly repetitive sequences due to short periodic repetitions in the chromosomes of Candida albicans. J. Bacteriol. 176: 3851-3858.

Chibana, H., Magee, B.B., Grindle, S., Ran, Y., Scherer, S., and Magee, P.T. 1998. A physical map of Chromosome 7 of Candida albicans. Genetics 149: 1739-1752.

Chindamporn, A., Nakagawa, Y., Homma, M., Chibana, H., Doi, M., and Tanaka, K. 1995. Analysis of the chromosomal localization of the repetitive sequences (RPSs) in Candida albicans. Microbiology 141: 469-476.

Chindamporn, A., Nakagawa, Y., Mizuguchi, I., Chibana, H., Doi, M., and Tanaka, K. 1998. The repetitive sequences, RPSs, in the chromosomes of Candida albicans, are sandwiched by two novel stretches HOK and RB2, common to each chromosome. Microbiology 144: 849-857.

Chu, W.S., Magee, B.B., and Magee, P.T. 1993. Construction of an $S f i$ macrorestriction map of the Candida albicans genome. $J$. Bacteriol. 175: 6637-6651.

Doi, M., Chibana, H., Nakagawa, Y., and Tanaka, K. 1998. Discrimination among the clinical isolates of Candida albicans by amplification of the repetitive sequences, alts. Microbiol. Immunol. 42: 227-230.

Fierro, F. and Martin, J.F. 1999. Molecular mechanisms of chromosomal rearrangement in fungi. Crit. Rev. Microbiol. 25: $1-17$.

Goodwin, T.J. and Poulter, R.T. 2000. Multiple LTR-retrotransposon families in the asexual yeast Candida albicans. Genome Res. 10: $174-191$.

Goshorn, A.K. and Scherer, S. 1989. Genetic analysis of prototrophic natural variants of Candida albicans. Genetics 123: 667-673.

Heery, D.M., Gannon, F., and Powell, R. 1990. A simple method for subcloning DNA fragments from gel slices. Trends in Genet. 6: 173 .

Herreros, E., Garcia-Saez, M.I., Nombela, C., and Sanchez, M. 1992. A reorganized Candida albicans DNA sequence promoting homologous non-integrative genetic transformation. Mol. Microbiol. 6: 3567-3574.

Hoyer, L.L., Magee, B.B., Rikkerink, E.H., and Scherer, S. 1994. The ARG4 gene of Candida albicans. Gene 142: 213-218.

Iwaguchi, S., Homma, M., and Tanaka, K. 1990. Variation in the electrophoretic karyotype analysed by the assignment of DNA probes in Candida albicans. J. Gen. Microbiol. 136: 2433-2442.

Iwaguchi, S., Homma, M., Chibana, H., and Tanaka, K. 1992a. Isolation and characterization of a repeated sequence (RPS1) of Candida albicans. J. Gen. Microbiol. 138: 1893-1900.

Iwaguchi, S., Homma, M., and Tanaka, K. 1992b. Clonal variation of chromosome size derived from the rDNA cluster region in Candida albicans.. J. Gen. Microbiol. 38: 1177-1184.

Iwaguchi, S-I., Kanbe, T., Tohne, T., Magee, P.T., and Suzuki, T. 2000. High-frequency occurrence of chromosome translocation in a mutant strain of Candida albicans by a suppressor mutation of ploidy shift. Yeast 16: 411-422.

Janbon, G., Sherman, F., and Rustchenko, E. 1998. Monosomy of a specific chromosome determines L-sorbose utilization: A novel regulatory mechanisim in Candida albicans. Proc. Natl. Acad. Sci. 95: 5150-5155.

Kim, U.J., Shizuya, H., de Jong, P.J., Birren, B., and Simon, M.I. 1992. Stable propagation of cosmid sized human DNA inserts in an F-factor-based vector. Nucleic Acids Res. 20: 1083-1085.

Kistler, T.G. and Miao, V.P.W. 1992. New modes of genetic change in filamentous fungi. Annu. Rev. Phytopathol. 30: 131-152.

Lasker, B.A., Carle, G.F., Kobayashi, G.S., and Medoff, G. 1989. Comparison of the separation of Candida albicans chromosome-sized DNA by pulsed-field gel electrophoresis techniques. Nucleic Acids Res. 17: 3783-3793.
Lasker, B.A., Page, L.S., Lot, T.J., and Kobayashi, G.S. 1992. Isolation, characterization, and sequencing of Candida albicans repetitive sequence element 2. Gene 116: 51-57.

Lott, T.J., Boiron, P., and Reiss, E. 1987. An electrophoretic karyotype for Candida albicans reveals large chromosomes in multiples. Mol. Gen. Genet. 209: 170-174.

Lott, T.J., Holloway, B.P., Logan, D.A., Fundyga, R., and Arnold, J. 1999. Towards understanding the evolution of the human commensal yeast Candida albicans. Microbiology 145: 1137-1143.

Louis, E.J., Naumova, E.S., Lee, A., Naumov, G., and Haber, J.E. 1994. The chromosome end in yeast: Its mosaic nature and influence on recombinational dynamics. Genetics 136: 789-802.

Magee, B.B. and Magee, P.T. 1987. Electrophoretic karyotypes and chromosome numbers in Candida species. J. Gen. Microbiol. 133: $425-430$.

. 1997. WO-2, a stable aneuploid derivative of Candida albicans strain WO-1, can switch from white to opaque and form hyphae. Microbiology 143: 289-295.

Magee, P.T., Bowdin, L., and Staudinger, J. 1992. Comparison of molecular typing methods for Candida albicans. J. Clin. Microbiol. 30: $2674-2679$

McEachern, M.J. and Hicks, J.B. 1993. Unusually large telomeric repeats in the yeast Candida albicans. Mol. Cell. Biol. 13: 551-560.

Mills, D. and McCluskey, K. 1990. Electrophoretic karyotypes of fungi: The new cytology. Mol. Plant-Microbe Interact. 3: 351-357.

Mori, T., Matsumura, M., and Oguri, T. 1998. Analysis by pulsed-field gel electrophoresis of Candida albicans that developed resistance during antifungal therapy. Nippon Ishinkin Gakkai Zasshi 39: 229-323.

Musial, C.E., Cockerill, F.R., and Roberts, G.D. 1988. Fungal infections of the immunocompromised host: Clinical and laboratory aspects. Clin. Microbiol. Rev. 1: 349-364.

Navarro-Garcia, F., Perez-Diaz, R.M., Magee, B.B., Pla, J., Nombela, C., and Magee, P.T. 1995. Chromosome reorganization in Candida albicans 1001 strain. J. Med. Vet. Mycol. 33: 361-366.

Perepnikhatka, V., Fischer, F.J., Niimi, M., Baker, R.A., Cannon, R.D., Wang, Y.K., Sherman, F., and Rustchenko, E. 1999. Specific chromosome alterations in fluconazole-resistant mutants of Candida albicans. J. Bacteriol. 181: 4041-4049.

Pujol, C., Reynes, J., Renaud, F., Raymond, M., Tibayrenc, M., Ayala, F.J., Janbon, F., Mallie, M., and Bastide, J.M. 1993. The yeast Candida albicans has a clonal mode of reproduction in a population of infected human immunodeficiency virus-positive patients. Proc. Natl. Acad. Sci. 90: 9456-9459.

Pujol, C., Joly, S., Lockhart, S.R., Noel, S., Tibayrenc, M., and Soll, D.R. 1997. Parity among the randomly amplified polymorphic DNA method, multilocus enzyme electrophoresis. and Southern blot hybridization with the moderately repetitive DNA probe Ca3 for fingerprinting Candida albicans. J. Clin. Microbiol. 35: $2348-2358$.

Pujol, C., Joly, S., Nolan, B., Srikantha, T., and Soll, D.R. 1999. Microevolutionary changes in Candida albicans identified by the complex $\mathrm{Ca} 3$ fingerprinting probe involve insertions and deletions of the full-length repetitive sequence RPS at specific genomic sites. Microbiology 145: 2635-2646.

Ramsey, H., Morrow, B., and Soll, D.R. 1994. An increase in switching frequency correlates with an increase in recombination of the ribosomal chromosomes of Candida albicans strain 3153A. Microbiology 140: 1525-1531.

Rustchenko-Bulgac, E.P. 1991. Variations of Candida albicans electrophoretic karyotypes. J. Bacteriol. 173: 6586-6596.

Rustchenko-Bulgac, E.P., Sherman, F., and Hicks, J.B. 1990. Chromosomal rearrangements associated with morphological mutants provide a means for genetic variation of Candida albicans. J. Bacteriol. 172: 1276-1283.

Rustchenko, E.P., Curran, T.M., and Sherman, F. 1993. Variations in the number of ribosomal DNA units in morphological mutants and normal strains of Candida albicans and in normal strains of Saccharomyces cerevisiae. J. Bacteriol. 175: 7189-7199.

Rustchenko, E.P., Howard, D.H., and Sherman, F. 1994. Chromosomal alterations of Candida albicans are associated with 
the gain and loss of assimilating functions. J. Bacteriol. 176: $3231-3241$.

Sadhu, C., McEachern, M.J., Rustchenko-Bulgac, E.P., Schmid, J., Soll, D.R., and Hicks, J.B. 1991. Telomeric and dispersed repeat sequences in Candida yeasts and their use in strain identification. J. Bacteriol. 173: 842-850.

Scherer, S. and Stevens, D.V. 1988. A Candida albicans dispersed, repeated gene family and its epidemiologic applications. Proc. Natl. Acad. Sci. 85: 1452-1456.

Slutsky, B., Buffo, J., and Soll, D.R. 1985. High-frequency switching of colony morphology in Candida albicans. Science 230: 666-669.

Snell, R.G. and Wilkins, R.J. 1986. Separation of chromosomal DNA molecules from C. albicans by pulsed field gel electrophoresis. Nucleic Acids Res. 14: 4401-4406.

Suzuki, T., Kobayashi, I., T. Kanbe, T., and Tanaka, K. 1989. High frequency variation of colony morphology and chromosome reorganization in the pathogenic yeast Candida albicans. J. Gen. Microbiol. 35: 425-434 .

Thrash-Bingham, C. and Gorman, J.A. 1993. Identification, characterization and sequence of Candida albicans repetitive DNAs Rel-1 and Rel-2. Curr. Genet. 23: 455-462.

Whelan, W.L. and Magee, P.T. 1981. Natural heterozygosity in Candida albicans. J. Bacteriol. 145: 896-903.

Wickes, B.L., Staudinger, J., Magee, B.B., Kwon-Chung, K.J., Magee, P.T., and Scherer, S. 1991. Physical and genetic mapping of Candida albicans: Several genes previously assigned to chromosome 1 map to chromosome R, the rDNA-containing linkage group. Infect. Immun. 59: 2480-2484.

Zolan, M.E. 1995. Chromsome-length polymorphism in fungi. Microbiol. reviews 59: 686-698.

Received May 23, 2000; accepted in revised form September 22, 2000. 


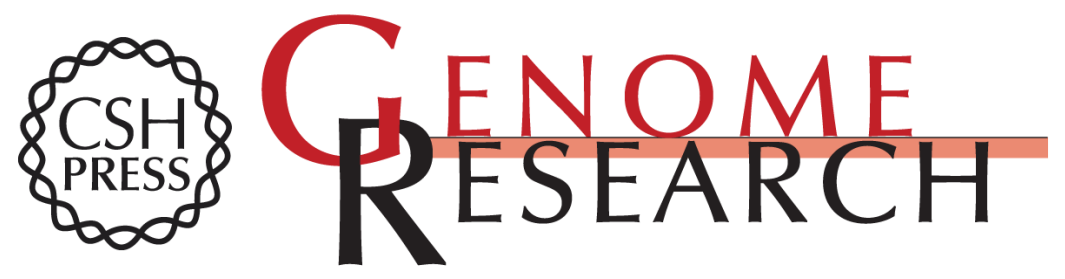

\section{Fine-Resolution Physical Mapping of Genomic Diversity in Candida albicans}

Hiroji Chibana, Janna L. Beckerman and P.T. Magee

Genome Res. 2000 10: 1865-1877

Access the most recent version at doi:10.1101/gr.148600

References This article cites 51 articles, 23 of which can be accessed free at:

http://genome.cshlp.org/content/10/12/1865.full.html\#ref-list-1

\section{License}

Email Alerting Receive free email alerts when new articles cite this article - sign up in the box at the Service top right corner of the article or click here.

\section{Affordable, Accurate Sequencing.}

To subscribe to Genome Research go to: https://genome.cshlp.org/subscriptions 